\title{
Prospects for the Application of Strategic Foresight in the Tunisian Context: The Case of Industrial Companies
}

\author{
Wided Ben Said ${ }^{1} \&$ Slaheddine Hellara ${ }^{2}$ \\ ${ }^{1}$ Faculty of Economic Sciences and Management of Tunis, University of Tunis El Manar, Tunisia \\ ${ }^{2}$ Higher Institute of Management of Tunis, University of Tunis, Tunisia \\ Correspondence: Wided Ben Said, Faculty of Economic Sciences and Management of Tunis, University of \\ Tunis El Manar, B.P 248 El Manar II, 2092 Tunis, Tunisia. Tel: 216-93-728-302. E-mail: \\ bensaid.wided@laposte.net
}

Received: March 6, 2013

doi:10.5539/ijbm.v8n15p99
Accepted: April 22, $2013 \quad$ Online Published: July 12, 2013

URL: http://dx.doi.org/10.5539/ijbm.v8n15p99

\begin{abstract}
If foresight aims at providing information and analyses which will allow better considering the uncertainties and the turbulences of the environment; strategic foresight would be a management tool which controls the necessity of ensuring the serious attempts of investigating the future before making decisions. The survival of the organization, its development and its evolution depends on this exploration.

Through this research, we have tried to describe the practice of strategic foresight by the Tunisian companies and consequently their capacity to adopt such approach.

More specifically, through an administered questionnaire with 39 industrial companies, we have tried to explain the factors allowing a better understanding of the mechanisms determining the companies' commitment in the field of strategic foresight.

The empirical results have shown that the adoption of strategic foresight by companies which would be reduced to the adoption of a preactive and a proactive attitude towards changes, would be the answer to the limitations of the classical methods of planning which the manager resorts to in his daily management, would require the implication of the various concerned actors, and finally, would be most of all interested in large companies. However, foresight tools do not seem to affect the companies' adoption of strategic foresight.

Thereby, for the Tunisian managers, strategic foresight is essentially perceived as a state of mind, an attitude facing the complexity of the problems they are confronting.
\end{abstract}

Keywords: foresight, strategic foresight, practice of strategic foresight, logistic regression

\section{Introduction}

Facing the increased uncertainties of the future, the lack of experience, and the impossibility to foresee the cycles which the companies are confronting, it is necessary to see far and wide, as it was recommended by the philosopher Gaston Berger (1957).

Thus, foresight is primarily a method of future exploration which consists in anticipating in order to enlighten possible futures. It becomes strategic when a company is interested in the possible evolutions of its environment as well as its own dynamics (Roubelat, 1998).

Although the researches which have dealt with the theme of foresight within the framework of a company are not numerous, we have noticed that even if they have emphasized the relation between foresight and strategy, they did not study the factors determining its practice.

Most of these researches have focused either in assessing the major practices of organizations in terms of strategic foresight (Roubelat 1996, 1998, Costanzo, 2004, Bootz and Monti, 2008, Rohrbeck and Gemünden, 2008, 2011, Bootz, 2010, Heger and Rohrbeck, 2012, Vecchiato, 2012, Rohrbeck and schwarz, 2013), or in describing the use of scenarios as a standard method for the consideration of a wide and long-term prospect within the framework of strategic foresight practice (Godet and Roubelat, 1996, Godet, 2000, Roubelat, 2000, 2006, Van der heijden, 2004, Bezold, 2010, Durance and Godet, 2010, Ringland, 2010).

Our research falls within the framework of foresight applied to management. More precisely, our purpose will 
be to answer the following question: What is the status of strategic foresight approach in the Tunisian context? In other words, what are the variables which can facilitate or make more difficult the adoption of such approach?

Therefore, we are trying through this research to describe strategic foresight practice by the Tunisian companies and consequently their capacity to adopt such approach.

In order to do so, we are going primarily, by referring to the literature, to introduce the notions of foresight and strategic foresight in order to better identify its practice.

Second, we are going to present the adopted research methodology and we are eventually going to explain and to discuss the results identified by the empirical validation.

\section{Theoretic Framework of the Research}

\subsection{Foresight: Questions of Terminology and Definitions}

In most of the texts dealing with the future, we have noticed the absence of consensus on the name or the definition of this activity. Indeed, unlike other disciplines, the studies and the researches oriented towards foresight cannot claim to a universally accepted terminology (Masini, 1993).

In this respect several terms, particularly "prospective", "foresight", "future research" and "future studies" are used interchangeably, without making any difference between the disciplines which they are meant to represent.

However, it should be noted that Roubelat (1998) distinguishes between foresight and "future researches" and "future studies", because he considers that these two disciplines are more general than foresight, which only represents a stream of thought among many others disciplines.

With respect to prospective and foresight, there is a strong similarity between these two concepts. The prospective stems from the same principle like foresight whereby the French translation of the word foresight is prospective (Masini, 1993, p. 22). It is in this direction that foresight legitimately falls in the evolution of prospective; indeed, it is a new aspect (Gonod and Gurtler, 2002).

Indeed, Rohrbeck and Schwartz (2013) consider that in the French tradition of "la prospective", foresight is related to critical thinking decision making and action. While in the American tradition, it is used as a means to describe a particular picture of the future. Therefore, it is narrower than the prospective.

We note in this regard, in our paper, we follow the suggestion of Coates, Durance and Godet (2010) to use strategic foresight's term and "la prospective" as synonymous.

Certainly, even if foresight is an art rather than a science, it would be generally considered, like the example of Lesourne (1989) as a technique or a set of techniques, the purpose of which is to enlighten the decision-maker both on the margins of freedom compared with the possible futures and the consequences of their decisions on the future.

Most of the definitions which we can find emphasis it's relation with action control, without excluding that this relation may not exist.

For Michel Godet, foresight is:

- $\quad$ "A panorama of the possible future of a system intended to enlighten the consequences of possible action strategies." (Godet, 1985, p. 32).

- $\quad$ "A reflection to enlighten the present action in the light of the possible future." (Godet, 1991, p. 10).

However, this relation between foresight and action is not strongly highlighted by other authors, who merely see it as an attempt to enlighten the shadows of the future.

According to Papon (2000), the foresight applied to research and technological development domain, loses this direct relation to action, without being totally absent. And Piganiol (2000), while emphasizing this relation with decision, similarly insists on the irrational dimension, the fears and the expectations which each person bears, which may spill over the representations of the future, to which results any foresight work.

The recent developments regarding prospective and foresight highlights the notion of participation. Thereby, Gavigan and Scapolo (2001, p. 2) define foresight as "a form of strategic analysis which involves a set of participatory processes consisting in collecting the intelligent systems of future analysis and to construct a vision to direct the decisions and the current actual actions."

Close to this definition, the report FOREN (2000, p. 3), gives the following definition of foresight "a systematic participatory process of construction of collective intelligence of the future and average or long-term visions 
aiming at enlightening the present decisions and at mobilizing the necessary means to undertake the common actions".

These two definitions crystallize the relation between prospective and foresight. Consequently, foresight appears as a systematic approach, which proposes the exploration of possible future, through the tools and the methods which allow the introduction of some discipline in a process which initially seems to be subjective.

It is equally a participatory process which involves all the concerned actors as well as an instrument which directs immediate decision-making according to the desired future.

Regardless of the adopted definition, foresight basically calls for a structure of thought and for common cultural references. In fact, "in its origin, there is a premise of freedom facing multiple and indefinite futures" (Godet, 1997, p. 23), hence its five fundamental characteristics: it is a comprehensive, long, rational approach, which enhances appropriation and which refers to a vision for action (Hatem, 1997, Smida, 2004).

\subsection{Foresight as a Field of Research and Application}

The first field of research and application which has developed foresight methodology was the military strategy. Afterwards, by taking into consideration the notion of uncertainty, foresight has been spread in management sciences.

Strategic foresight reveals the emergence of foresight attitude in the company. Foresight has became integrated into management literature since the mid-1980s (Godet, 1985).

First, this integration was carried out starting from techniques used in foresight, particularly, the scenarios. For Van Der Heijden (1997), foresight or at least the approaches by scenarios, refers to the main approaches in strategy, whether it is about the rationalist, the evolutionist or the process approach.

In this framework, Van Der Heijden (2004) has assessed the use by the organizations of planning by scenarios. The author advocates that scenarios have a role to play in strategies elaboration and in learning.

Nowadays, strategic foresight becomes a research domain within the framework of strategic management. Consequently, as a research field in strategic management, strategic foresight, does no longer fall under the unique domain of techniques such as scenarios, but must also be understood in terms of process (Roubelat, 1998).

Thereby, foresight practice should no longer be limited to scenarios construction, because several confusions might spring from this situation, which would make the link between foresight and strategy difficult (Destatte, 2008).

\subsection{Strategic Foresight, Definitions and Principles}

According to Roubelat (1998), foresight is a process of intellectual innovation which consists on understanding the future; and it becomes strategic when the organization becomes interested in the possible changes of its environment as well as in its dynamics.

Whereas, Slaughter (1997) considers that strategic foresight represents the amalgamation between future and strategic management methods.

Thereby, as an activity of strategic management, strategic foresight would be according to Roubelat (2001-a) " $a$ process of networks animation intended to question the representations of the various actors shaping the company and its environment, through a collective reflection on the possible future in order to direct the strategy of the organization".

Thus, strategic foresight analyzes the future as a multiple reality. It means that there is no one future, but several and that a question could have more than one answer (Mojica, 2010).

Specifically, strategic foresight helps companies to renew itself (Ringland, 2010) and aims at examining how they manage identifying, anticipating and managing the disturbances and getting ready for an uncertain future (Rohrbeck and Gemünden, 2008).

In this sens, Rohrbeck and Schwartz (2013, p.2), focus on the ability of strategic foresight to add value to a corporate organization through several ways namely, enhancing capacity to perceive change, enhancing capacity to interpret and respond to change, influencing other actors, and enhancing capacity for organizational learning.

By assessing the application of strategic foresight in an American prospect, Coates (2010) considers that for the American futurists the flexibility in methods and techniques of strategic foresight, as it is practiced, is the most important characteristic. 
As for strategic foresight in a French prospect, the author considers that it makes an interesting and maybe useful distinction between preactivity and proactivity. The first as being prepared for the expected changes and the second is acting in response to external changes which are uncertain or potential.

Indeed, Michel Godet (1997, p. 9) distinguishes in this respect four attitudes which can be taken to deal with the future's uncertainty and potentialities, which are: passivity, reactivity, preactivity and proactivity.

The combination between the concepts of "preactivity" and "proactivity" gives the exact definition of foresight contents or attitude (Godet and Roubelat, 1996). Thereby, this attitude becomes a vital necessity for companies because it helps them manage the change which may affect their environment.

Furthermore, strategic foresight is the art of putting anticipation in the service of action. Yet, as explains it Kalika (1991), a proactive organization should possess formal or non-formal strategic foresight bodies. The link between scanning and foresight is hence more obvious than in the approach of Jouvenel (1999) who considers that foresight thrives on scanning and that it represents in the present case, a major component in foresight methods.

\subsection{Practice of Strategic Foresight}

In attempting to answer the question: how to conduct strategic foresight? It is essential to understand the determining elements to get an effective foresight. Destatte (2008) distinguishes three elements:

- To conceive foresight practice as a collective process of acculturation and learning of all those who are going to implement the strategy.

- To have the capacity to vigorously, but also simply absorb the complexity.

- To be modest. Indeed, the modesty of the future analyst induces intellectual openness, interdisciplinarity, scanning, vigilance and flexibility.

Strategic foresight appears, as network animation activity involving human, information and communication networks (Roubelat, 2001-b).

Actually, it's according to Gaston Berger (1957) a matter of making experts of various domains work together, "a philosopher, a psychologist, a sociologist, an economist, etc".

Consequently, in order to organize foresight practice in a company, it is necessary to have experts' database (academic, institutional, professional, etc.) likely to be accessed or mobilized in working groups for scenarios construction.

Indeed, Reibnitz (2003) considers that in order to conduct a strategic foresight process, it is mandatory to involve the decision-makers, the appropriate experts and the people in charge (marketing, R \& D, management control, and human resources managers, etc.).

Foresight thus becomes, a practice of sense-making (Roubelat, 1998) and mobilization around a project (Lesourne, 1985), where the appropriation of foresight reflections by all the actors of the company, is as important as the result of the practice in terms of decision-making support (Godet, 1997) and where the experts should abstain in order to become actors among the other actors of foresight reflection (Thiétard and Bergadaa, 1990).

Through the constitution of human, expert and decision-making networks, the object of strategic foresight is to assert the required variety through a systematic approach, starting from vast information networks (Lesourne, 1996, p. 56).

On a more technical plan concerning the implementation of foresight, the first researches on the subject have focused on the definition of the procedures allowing not only to structure the information stemming from these networks but also to structure the process of communication with the experts (Roubelat, 1998).

The dissemination of Information Technologies and Communication (ICT) makes the question of the technological dimension of foresight network increasingly important, since it involves both the internal and the external actors of the organization (Roubelat, 2000).

In this respect, strategic foresight will be used as a tool of individual and collective learning and it will establish a practice of questioning the strategic paradigms (Roubelat, 2006).

Heger and Rohrbeck (2012) consider that in a French tradition, strategic foresight is seen as a learning process through which the future is invented and created.

Within this framework, Bootz (2010) have tried, through a critical examination to clarify the nature of the link 
between strategic foresight and organizational learning while analyzing the cognitive dimensions of foresight.

He has concluded that with scenarios, the futurist tries to achieve a real educational work trough offering to the decision-makers new future analysis grid different from their usual mental modals, while emphasizing the main risks and opportunities they are likely to encounter.

Through a case study conducted in financial services industry in the United Kingdom and based on qualitative data resulting from semi-structured interviews conducted with some managers, Costanzo (2004) have shown that the development of strategic foresight is a learning process which takes place in a broad vision and which stipulates the future with a survey mechanism, through several less expensive devices.

The results suggest that having agility, visible and structured processes, expanding communication and a focused and eccentric management group allow the formation of a basic set which influences the capacity of the company to develop strategic foresight and to permanently innovate without collapsing.

Based on a set of explorative case studies, Vecchiato (2012) had analysed how the foresight practices and techniques are coordinated throughout several companies and how their results are used for supporting strategic decision making.

The author had presented the strategic foresight activities as a learning process planned for the future. Indeed, in connexion with decision making under uncertainty, strategic foresight activities allow managers to detect opportunities and threats in advance and to respond more effectively when they start to emerge.

If Bootz and Monti (2008) have tried to assess foresight practices with the aim of suggesting a typology which would constitute a means of interpreting allowing the practitioners to conceive and to conduct adapted foresight approach, several authors have focused on the critics directed against strategic foresight practice.

In this respect, De Montmorillon (2008), Scouarnec (2008) and Destatte (2008) have argued for foresight renewal, through the renewal of the approaches, the methods and the tools in order to better serve the managerial practices.

More recently, Rohrbeck and Gemünden (2011) have tried to study the way in which foresight should be integrated in the effort of innovating the company based on empirical data from 19 case studies and 107 interviews. They have identified three roles which company foresight should play in order to maximize the innovation capacity of the company, namely, the roles of the strategist, the initiator and the opponent.

\section{Methodological Framework of the Research}

\subsection{The Suggested Conceptual Model}

In order to highlight the variables which facilitate or make the adoption of strategic foresight difficult, we have opted for the construction of a model allowing us to answer the object of our research: describe strategic foresight practice in the Tunisian context and consequently the capacity of the Tunisian companies to adopt such approach.

In order to do so, we have based ourselves on the literature review as well as on an exploratory study which we have conducted with some consultants or practitioners in the field of foresight (Tunisian Institute for Strategic Studies (ITES), National Institute of Quantitative Studies (INEQ), consulting offices and company directors of different sizes (small, average and big).

Thereby, the interviews which we have realized are meant to direct us to choose the variables and the measure indicators, and to outline the profile of companies which are meant to constitute the survey ground.

Consequently, based on the obtained answers, we were able to specify our research avenues. Indeed, five factor groups have been formed to better understand the mechanisms determining the commitment in strategic the field of foresight.

These five factor groups are as follows: the attitude facing the future (ATTAF), the insufficiency of classical methods of foresight (INSME), the implication of foresight actors (IMPACT), the use of foresight tools (FORETOO) and the size of the company (SIZE).

Besides, the adoption of strategic foresight (FORESIGHT) depends on these five factors; we have diagrammed this relation as follows:

FORESIGHT $=\mathrm{f}($ ATTAF, INSME, IMPACT, FORETOO, SIZE)

Besides, in order to equate this relation, we bring it down to a linear and additive mathematical model:

$$
Y=a_{0}+a_{1} x_{1}+a_{2} x_{2}+a_{3} x_{3}+\ldots \ldots \ldots \ldots+a_{n} x_{n}+\varepsilon_{i}
$$


The model is said linear because the relation between $\mathrm{Xi}$ and $\mathrm{Y}$ can be expressed geometrically by a straight line (Xi, Y). It is additive because the effects of the explanatory variables on Y are simply added (Lambin, 1993).

The linear regression is a modelling technique; its objective is to discover how one or several variables (called independent, predictive or explanatory variables) affect other variables (called dependent variables or variables to be explained).

Afterwards, we formulate the following regression:

$$
\text { FORESIGHT }=a_{0}+a_{1} \text { ATTAF }+a_{2} \text { INSME }+a_{3} \text { IMPACT }+a_{4} \text { FORETOO }+a_{5} \text { SIZE }+\varepsilon_{i}
$$

The identified measurement scales were purified, by the calculation of Crombach's Alpha in order to ensure their good representativeness, their reliability and their validity.

We consider that for an exploratory study, Crombach's Alpha has to exceed the value of 0,7 . In this research, Crombach's Alpha is between 0, 7342 and 0, 9342; what represents a satisfactory value.

\subsection{Data Collection}

This research suggests establishing a descriptive study to attempt to explore the applicability degree of strategic foresight by the Tunisian companies.

The targeted population of this research is the managers of the industrial Tunisian companies.

We have chosen the managers as target of this research, since they generally have, as part of their function in the organizational structure, the necessary experience allowing them to have a global vision and to be alert for all what concerns their organizations' sustainability. That is why we address the general directorate, in order to conduct our study.

The choice of the industrial branch can be motivated by the fact that Tunisia is endowed with an expanding industrial sector. It comprises 5698 company among which 2670 are wholly exporting. These companies mainly operate in agri-food (1047 company), textile and clothing (1881 company) and mechanical and metallurgical (620 company) industries.

In order to identify the individuals susceptible to constitute our sample, we have resorted to a non-probability sampling method. It is a quotas method which consists in reproducing the same model of the relevant population. In order to achieve this, we have resorted to the database of the Agency for the Promotion of Industry (A. P. I.). (Note 1)

In this way we have selected $10 \%$ of the companies from each sector, situated in the governorate of Tunis, to have by the end 50 companies. However, taking into account the constraint of the availability of managers and their agreement to kindly participate in the study, we were able to make an appointment with 39 managers in our sample. We had thus a response rate of $78 \%$. The definitive sample thus concerns only 39 industrial companies.

In order to conduct this research, we have chosen to realize a quantitative study. And, this is why we have chosen the survey questionnaire methodology.

The questionnaire design was progressively made. Indeed, once elaborated, we have submitted it to a pre-test first phase with a foresight professional, a university teacher of " administrative foresight", and three managers from our sample, in order to verify the understanding, the questions' statement order as well as the convenience of the presented answers modalities.

This phase has allowed us to retain the most appropriate, the simplest and the most comprehensible version of our questionnaire. It comprises about twenty questions organized in six parts.

The first part includes data of general order about the respondents (hierarchical level in the organizational structure, academic background), and of the company (business sector, turnover, total number of the staff, does or does not belong to a group).

The second part is interested in describing the commitment of companies in the field of foresight. The third part focuses on the managers' attitude facing the future. This part tries to define the future, to characterize the environment complexity, to estimate the consideration of the environment complexity in strategic reflection, and to wonder about the attitude which would be adopted facing future hazards.

The fourth part describes the managers' perception concerning the insufficiency of the classical methods of planning and their consequences. The fifth part estimates how to conduct a foresight reflection in the organization and focuses on whether or not the company uses experts or consultants in order to enlighten the future choices and finally, the sixth part is related to foresight methods and particularly scenarios method. 
In order to administrate the questionnaire of our survey, we have opted for direct contact through the "face-to-face" method after fixing an appointment. Indeed, this procedure has allowed us to avoid statements' misunderstanding and to intervene, where necessary, to clarify certain misunderstood or misinterpreted concepts.

Thereby, we have contacted and fixed appointments with 39 managers from our sample, according to their availability. They were asked to answer unique or multiple choice closed-ended questions. Likert scale with five choices has been also used going from "strongly disagree" to "strongly agree".

We would also like to clarify that the questionnaire administration has lasted approximately 3 months and that some interviews were full of learning and lasted from 45 minute to one (1) hour.

\section{Results}

The data analysis of our research focuses on the validation of the conceptual model which we have suggested. The model of causal analysis which we adopt is regression. This method is used in its logistic version; it aims at explaining and describing the phenomena, in the present case it is the commitment in the field of foresight.

The logistic regression belongs to the family of "log-linear" models. It allows the study of the relations between the qualitative variables, the variable to be explained is often a binary variable $(0,1)$.

4.1 Results of the MCA (Multiple Correspondence Analysis), the PCA (Principle Component Analysis) and the Preliminary Tests in Regression

- We have submitted the items corresponding to our independent variables: the attitude facing the future (ATTAF), the insufficiency of classical methods of foresight (INSME), the implication of foresight actors (IMPACT), the use of foresight tools (FORETOO), to the MCA, in order to explore the relations which they maintain and subsequently produce a unique measure.

The "proper values" allow showing whether the resulting dimensions of the MCA, are well determined by the items of each variable.

The "discrimination measures" provide information about the contribution of each item in the dimension. This contribution is also graphically displayed.

We have submitted the dimensions identified from the MCA to a reliability test in order to make sure of the internal coherence of each dimension.

The dimension which has presented an acceptable Crombach's Alpha has been introduced into the logistic regression model.

- An ACP has been used to alleviate the multidimensionality of the variable "SIZE" and to extract a common factor of the number of total turnover.

The retained factor (REGR factor size) has a proper value of 1,887 , represent $94,371 \%$ of the total explained variance and it is reliable because it presents a Crombach's Alpha of 0,9342 .

- Preliminary tests in regression have been applied to the regression model, particularly the multicollinearity test.

The tolerance values are almost close to 1, all the "VIF" values are lower than 3 and the values of the condition number are lower than 15 .

The absence of multicollinearity at the level of the explanatory variables is thereby confirmed.

Consequently, by taking into consideration the model's variables and their retained dimensions, the equation simplifies to:

$$
\begin{gathered}
\text { FORESIGHT }=a_{0}+a_{1} \text { ATTAFD2 }+a_{2} \text { INSMED } 1+a_{3} \text { IMPACTD } 1+a_{4} \text { FORETOO D } 1+a_{5} \text { REGR factor } \\
\text { SIZE }+\varepsilon i
\end{gathered}
$$

Where:

FORESIGHT is the commitment in strategic foresight; ATTAFD2 is the $2^{\text {nd }}$ dimension of the variable attitude facing the future, INSMED1 is the $1^{\text {st }}$ dimension of the variable insufficiency of classical methods of foresight, IMPACTD1 is the $1^{\text {st }}$ dimension of the variable implication of foresight actors, FORETOOD1 is the $1^{\text {st }}$ dimension of the variable the use of foresight tools, REGR factor size is the common factor of the variable size. 


\subsection{Results of the Logistic Regression}

\subsubsection{Tests of the General Significance of the Model}

According to the results provided by SPSS software, the equation of our model (which we have presented above) simplifies to:

$$
\begin{aligned}
\text { FORESIGHT }= & (0.784)+(2.943) \text { ATTAFD } 2+(5.796) \text { INSMED1 + (4.523) IMPACTD1+ } \\
& (-0.267) \text { FORETOOD } 1+(4.915) \text { REGR factor size }+\varepsilon i
\end{aligned}
$$

The purpose of the test of general significance is to make sure that all the variables of the model ATTAFD2, INSMED1, IMPACTD1, FORETOOD1 and REGR factor size have a significant explanatory power.

Before explaining the results relative to this test, we shall first of all present the characteristics of M0 model, in which no explanatory factor is taken into consideration, except the constant.

Table 1. Summary of M0 model

\begin{tabular}{cccccccc}
\hline Stage & B & E.S. & Wald & ddl & Signif. & Exp (B) & -2LogLik \\
\hline $\begin{array}{c}\mathbf{0} \\
\text { Constant }\end{array}$ &, 580 &, 334 & 3,017 & 1 &, 082 & 1,786 & 50,920 \\
\hline
\end{tabular}

The indicators on the quality of the model's general adjustment are given by:

1) -2 log likelihood

Table 2. Summary of M1 model

\begin{tabular}{cccc}
\hline Stage & -2LogLik & Cox \& Snell R2 & Nagelkerke's R2 \\
\hline $\mathbf{1}$ & 13,126 &, 621 &, 851 \\
\hline
\end{tabular}

It appears from table 2 that - $2 \log$ likelihood (-2LL) worth 13.126 in our model. We notice that the adjustment of the model is much better when its credibility is strong, and its -2Loglik is small.

According to tables 1 and 2, we observe that the adjustment of the specified model, $-2 \mathrm{LL}(\mathrm{M} 1)=13.126$ is better than that of the model without explanatory factors, 2LL (M0) $=50.920$.

2) The statistics of the khi-squared.

Table 3. Tests of the model specification

\begin{tabular}{cccc}
\hline Stage & Khi-squared & ddl & Signif. \\
\hline $\mathbf{1}$ & 37,794 & 6 &, 000 \\
\hline
\end{tabular}

As show in table 3, the value of "Khi-squared" is 37.794. This is big for $p=6$ freedom degrees, what confirms the meaning degree.

3) Likelihood ration test

This test is given under "Khi-squared". In a particular case, there is a change between blocks 0 and 1 . We have indeed verified that we have:

$$
D=-2 L L(M 0)-(-2 L L(M 1))=50.920-13.126=37.794
$$

We have noticed that this test replaces Fisher test in multiple regression.

4) The pseudo $R^{2}$

Which are presented in our context by those of Cox \& Snell $\left(\mathrm{R}^{2} \mathrm{CS}\right)$ and Nagelkerke $\left(\mathrm{R}_{\mathrm{N}}^{2}\right)$. In our model, as shown in table 2 , we have $\mathrm{R}^{2} \mathrm{CS}=0.621$ and $\mathrm{R}_{\mathrm{N}}^{2}=0.851$. Thus, we can conclude that the explained part of the total dispersal is $70 \%$.

After verifying that our model is generally significant, we have moved to the interpretations of the individual coefficient significance test; in order to determine the relevance of each independent variable. 


\subsubsection{Individual Significance Tests}

The procedure of regression by SPSS software gives for each coefficient including Wald statistics, its liberty and Significance degrees.

However, the procedure does not give ratio-critic, named $t$ of Student, between the coefficient and its standard error which we traditionally examine in order to judge its statistical significance.

Table 4. Variables in the equation

\begin{tabular}{lllllll}
\hline Stage 1a & B & E.S. & Wald & ddl & Signif. & Exp(B) \\
\hline ATTAFD2 & 2,943 & 1,502 & 3,841 & 1 &, 050 & 18,967 \\
INSME D1 & 5,796 & 2,533 & 5,235 & 1 &, 022 & 328,882 \\
IMPACT D1 & 4,523 & 2,184 & 4,288 & 1 &, 038 & 92,086 \\
FORETOO D1 &,- 267 &, 523 &, 261 & 1 &, 610 &, 766 \\
REGR Factor Size & 4,915 & 2,447 & 4,033 & 1 &, 045 &, 007 \\
VARmuette obs33 & $-17,173$ & 60,591 &, 080 & 1 &, 777 &, 000 \\
Constant &, 784 &, 850 &, 850 & 1 &, 357 & 2,190 \\
\hline
\end{tabular}

a. Variable (s) which moved to stage 1: ATTAF D2, INSME D1, IMPACT D1, FORETOO D1, REGR factor size, and VARmuette obs33

By examining table 4 , we have noticed that Wald statistics is significant at $5 \%$ and at 1 degree of freedom for the variables ATTAFD2, INSME D1, IMPACT D1, and REGR factor size, and not the variable FORETOOD1.

It remains to determine how the explanatory factor acts on the dependent variable. In order to do so, we have resorted to the sign of the estimated coefficient (B) of each explanatory factor. If the sign is $(+)$ we consider that the explanatory factor has a positive effect on the dependent variable and vice versa.

In our case, this sign is positive for variables ATTAFD2, INSMED1, IMPACTD1, and REGR factor SIZE while it is negative for the variable FORETOOD1. Thereby we conclude that the adopted attitude facing future hazards, the insufficiency of foresight methods, the implication of foresight actors, and the size of the company significantly affect the commitment in the field of foresight and positively act on this commitment. On the other hand foresight tools do not seem to affect the adoption of strategic foresight by the companies.

\section{Results Discussion}

The major practices of foresight highlight a general and transversal attitude towards the future, interactive and participative analysis methods and support decision making.

The practice of foresight in the Tunisian companies is still recent and limited, however it seems expanding. In fact, $82 \%$ of the interviewed managers stated that the main obstacles to their commitment in the field of foresight are the financial means. Nevertheless they want to enhance their efforts in this domain.

The results show that strategic foresight adoption would be reduced to the adoption of a preactive and proactive attitude facing the changes.

Moreover, an organization which adopts a passive attitude facing the future can never be considered as committed in the field of foresight.

The reasons which urge the organizations to adopt foresight attitude address their perception of the future and its complexity.

Indeed, if the future is multiple in the sense that its open to several possible futures, the complexity which is characterized by the impossibility to predict the future by calculation, even in probability, establishes for the most of the interviewed managers ( $82 \%$ of our sample) a constraint which should be taken into consideration at the level of their strategic reflection.

In other words, the nature of the attitude which the company adopts facing the future's hazards, positively influences its interest in long-term directed questions as well as foresights reflections.

Consequently, the more the company tries to be flexible and proactive to be able to react and to adapt itself to the environment, the more its adoption of strategic foresight would be confirmed. 
The results have also shown that the insufficiency of traditional foresight methods positively acts on the commitment in the field of foresight.

Indeed, more the decision-maker is aware of the limitations of the traditional methods of planning for which he resorts in his daily management, the more he feels the need for strategic foresight as a new approach allowing him not to control, but to survive and to develop in an increasingly turbulent and even complex environment.

Foresight methods show several inadequacies which are mainly criticized. Indeed, without claiming that they are totally exhaustive, we note that these methods:

- Provoke foresight errors of judgment, consequently it is impossible for us to grant them total trust.

- Failed to adapt themselves to the acceleration of change and uncertainty.

- Tend to concentrate on short term, while they have to incorporate long-term foresight. Indeed, in short term, we react while in long term, we act.

- Do not allow to develop a common vision of the future because they do not encourage the use of the interactive and participative methods of analysis and decision support by basing itself on dialogue.

- Drawn on determinist and quantitative models. However, it is essential to use methods drawn on quantitative and qualitative variables in order to explore the future potentialities.

- Are not generally designed to consider the cultural and political dimension of the organization: the individuals' will and the motivation of the groups which are often ignored herein.

- Allow determining a strategy which risks being relevant by the whole organization.

- Define a plan and not a general strategic orientation which authorizes certain freedom of movement.

The results have allowed us to note that the involvement of foresight actors would be necessary for its adoption by the companies. Indeed, they positively act on the commitment in the field of foresight.

More precisely, a strong approval from the manager, his participation with the team in charge of the mission of foresight, the choice of this team according to certain criteria (age, experience, training, etc.), the recourse to a group of experts (external and/or internal) likely to be consulted or even mobilized in working groups, and finally, the participation of the concerned staff through discussion meetings over their future vision; constitute the essential requirements without which a company cannot be committed in strategic foresight.

Furthermore, the involvement of the relevant actors in the foresight reflection presents several advantages:

- It increases the decision-makers' capacity to better master uncertainties.

- Makes them feel and understand future changes.

- Intensify the reactivity and proactivity capacity of the company.

- And encourage the managers to address the challenges.

However, the results have shown that foresight tools do not seem to affect the adoption of strategic foresight by the companies. Indeed, we have noticed that the majority of the interviewed decision-makers do not know (and thus do not use) foresight methods (except scenarios and Delphi method).

Thereby, for the Tunisian managers, strategic foresight is not defined by the use of foresight methodologies.

In other words, a company can be committed in the field of foresight without using its specific methods.

This may be explained by the fact that strategic foresight is essentially perceived as a state of mind, an attitude facing the complexity of the problems confronted by the company.

Most of the questioned managers have declared to have a quite old practice of planning, unlike foresight approach which is much more recent.

Similarly, we have noticed that they are, generally, unfamiliar with foresight literature and the existing tools in the field of foresight.

We have identified that scenarios method and Delphi method were the most known and the only used (by a restricted number of companies) among the foresight methods which we have proposed.

Indeed, the scenarios method is known by $66,7 \%$ of the managers of our sample against $51,3 \%$ for Delphi method, and $15,4 \%$ for structural analysis.

As for the use of these tools, Delphi method is practiced only by $17,9 \%$ of the companies of our sample, against $7,7 \%$ for the scenarios method. 
The reasons justifying not using the scenarios method by the companies are essentially financial $(44,44 \%)$ and also due to the formalized nature of the method $(30,55 \%)$ as well as its length $(25 \%)$.

Similarly, foresight methods remain rather less known compared to strategic analysis tools (life cycle, experience effect, business portfolio, strategic segmentation, value chain, etc.), which are better known. The majority of the questioned managers ( $79,48 \%$ that is 31 managers) have declared to know these tools. This can be explained by the economic nature of their academic background.

Finally, we could say that the results have allowed us to show that the relation between the size of the company and the commitment in the field of strategic foresight is positive.

Otherwise, the exploratory study which we have conducted has allowed us to notice that generally, concretely practicing foresight, in the sense of enduring in the future, is essentially reserved for big or medium sized enterprises.

Several managers of small and medium-sized enterprise, mostly don't have a reflection horizon for more than 4 years, they have explained for us their incapacity to make a foresight commitment, because of the size of the enterprise and naturally due to the lack of financial means.

Actually, the more the company is big, the more the interest in foresight reflection is important, with the increasing need to recognize the latter as an independent function in the organizational structure and to grant it the most significant means (models, seek external consultants, etc.)

By taking part in the history of foresight, we shall find that this result is in accordance with the situation both on the European and the Anglo-Saxon plan, where strategic foresight has always been the privilege of industrial large companies which were confronted with long-term investments choices committing their future.

\section{Conclusion}

The purpose of this research was to discuss on the one hand, the applicability degree of strategic foresight by the Tunisian companies and on the other hand, the prospects of such approach in the Tunisian context.

Therefore, this study has contributed in the understanding and the explanation of the practices of the Tunisian industrial companies regarding foresight.

In order to do so, we have tried to construct a model highlighting the variables which are able to facilitate or to make the adoption of strategic foresight more difficult. In this respect, we have created and validated new measurement scales.

Our results have allowed us to conclude that, the adopted attitude facing future hazards, the insufficiency of foresight methods, the implication of foresight actors, and the size of the company significantly affect the commitment in the field of foresight and positively act on this commitment.

On the other hand, the results have shown that foresight tools do not seem to affect the adoption of strategic foresight by the companies.

However, this research has certain limitations; the most important of them reach these levels:

- At the level of the results' external validity, we cannot aspire to a generalization of these overall the Tunisian companies, because of the (reduced) size and of the nature (non-probabilistic) of our sample.

The consideration of this limitation gives us the opportunity to consider a research avenue based on the constitution of a larger sample composed of companies belonging to all the sectors, in all the regions of the country, which might be the object of an analysis accentuating more the practice of strategic foresight by Tunisian companies.

- At the methodological level, our choice to construct our own measurement scale can be considered as a limitation and thereby biases our data processing.

- Besides, the errors of observation such as the misunderstanding of the respondents of certain points in the questionnaire, the manipulation of the subject and the subjectivity of the researcher might be considered as one other limitation in this study.

Nonetheless, in spite of these limitations, the prospects of pursuit and deepening are numerous, especially with respect to foresight and information systems management through the study of the impact of information and communication technologies (ICT) on the implementation of strategic foresight.

\section{References}

Berger, G. (1957). Sciences humaines et prévision. Revue des deux mondes. 
Bezold, C. (2010). Lessons from using scenarios for strategic foresight. Technological Forecasting Social Change, 77, 1513-1518. http://dx.doi.org/10.1016/j.techfore.2010.06.012

Bootz, J. Ph. (2010). Strategic foresight and organizational learning: A survey and critical analysis. $\begin{array}{lllll}\text { Technological Forecasting } \quad \& \quad \text { Social } & \text { Change, } & 77, & \text { 1588-1594. }\end{array}$ http://dx.doi.org/10.1016/j.techfore.2010.06.015

Bootz, J. Ph., \& Monti, R. (2008). Proposition d'une typologie des démarches de prospective participative pour les entreprises. Trois cas illustratifs: EDF R \& D, AXA France et BASF Agro. Management \& Avenir, 5(19), 114-131. http://dx.doi.org/10.3917/mav.019.0114

Coates, J. F. (2010). The future of foresight-A US perspective. Technological Forecasting \& Social Change, 77, 1428-1437. http://dx.doi.org/10.1016/j.techfore.2010.07.009

Coates, J., Durance, P., \& Godet, M. (2010). Strategic foresight issue: introduction. Forecasting \& Social Change, 77(9), 1423-1425. http://dx.doi.org/10.1016/j.techfore.2010.08.001

Costanzo, L. A. (2004). Strategic foresight in a high-speed environment. Futures, 36, 219-235. http://dx.doi.org/10.1016/S0016-3287(03)00145-9

De Montmorillon, B. (2008). Nouveaux enjeux de la prospective à la lumière de la théorie des organisations. Management \& Avenir, 5(19), 11-12. http://dx.doi.org/10.3917/mav.019.0011

Destatte, Ph. (2008). S'inscrire dans un renouveau de la prospective européenne et favoriser une meilleure adéquation de ses méthodes. Management \& Avenir, 5(19), 13-17. http://dx.doi.org/10.3917/mav.019.0013

Durance, P., \& Godet, M. (2010). Scenario building: Uses and abuses. Technological Forecasting \& Social Change, 77, 1488-1492. http://dx.doi.org/10.1016/j.techfore.2010.06.007

FOREN (Foresight for Regional Development Network). (2000). Reconciling Foresight with Policy Making at Regional Level.

Gavigan, J. P., \& Scapolo, F. (2001). Prospective et vision à long terme dans le développement régional. The IPTS Report, 56.

Godet, M. (1985). Prospective et planification stratégique. Economica.

Godet, M. (1991). Les dangers de la (seule) Réactivité. Revue Française de Gestion, 86.

Godet, M., \& Roubelat, F. (1996). Creating the future: the use and misuse of scenarios. Long Range Planning, 29(2). http://dx.doi.org/10.1016/0024-6301(96)00004-0

Godet, M. (1997). Manuel de prospective stratégique. Tome1: Une indiscipline intellectuelle. Dunod, Paris.

Godet, M. (2000). The art of scenarios and strategic planning: tools and pitfalls. Technological Forecasting Social Change, 65, 3-22. http://dx.doi.org/10.1016/S0040-1625(99)00120-1

Gonod, P. F., \& Gurtler, J. L. (2002). Evolution de la prospective. $O C L, 9(5), 317-328$.

Hatem, F. (1997). Prospective stratégique. Encyclopédie de gestion. Economica, 2664-2674.

Heger, T., \& Rohrbeck, R. (2012). Strategic foresight for collaborative exploration of new business fields. Technological Forecasting \& Social Change, 79, 819-831. http://dx.doi.org/10.1016/j.techfore.2011.11.003

Jouvenel, H. (1999). Sur la démarche prospective : un bref guide méthodologique. Revue Futuribles, 247.

Kalika, P. (1991). De l'organisation réactive à l'organisation anticipatrice. Revue Française de Gestion, 86.

Lambin, J. J. (1993). La recherche en marketing, analyser, mesurer, prévoir. Economica.

Lesourne, J. (1985). Vers un retour en grâce de la prévision et de la prospective. Revue Française de Gestion, 53-54.

Lesourne, J. (1989). Plaidoyer pour une recherche en prospective. Futuribles, 137.

Lesourne, J., \& Stoffaes, C. (1996). La prospective stratégique d'entreprise: Concepts et études de cas. Inter Editions, Paris.

Masini, E. B. (1993). Why futures studies? Grey Seal Books, London.

Mojica, F. J. (2010). The future of the future: Strategic foresight in Latin America. Technological Forecasting \& Social Change, 77, 1559-1565. http://dx.doi.org/10.1016/j.techfore.2010.07.008

Papon, P. (2000). Recherche scientifique. Encyclopaedia Universalis. 
Piganiol, P. (2000). Prospective et futurologie. Encyclopeadia Universalis.

Reibnitz, H. (2003). Réussir dans une période de bouleversements. Revue Echanges, 196.

Ringland, G. (2010). The role of scenarios in strategic foresight. Technological Forecasting \& Social Change, 77, 1493-1498. http://dx.doi.org/10.1016/j.techfore.2010.06.010

Rohrbeck, R., \& Gemünden, H. G. (2008). Strategic Foresight in Multinational Enterprises: Building a Best-Practice Framework from Case Studies. R \& D Management Conference Emerging methods in R \& D management, Ottawa, Canada.

Rohrbeck, R., \& Gemünden, H. G. (2011). Corporate foresight: Its three roles in enhancing the innovation capacity of a firm. Technological Forecasting \& Social Change, 78, 231-243. http://dx.doi.org/10.1016/j.techfore.2010.06.019

Rohrbeck, R., \& Schwarz, T. O. (2013). The value contribution of strategic foresight: Insights from an empirical study of large European companies. Technological Forecasting \& Social Change. http://dx.doi.org/10.1016/j.techfore.2013.01.004

Roubelat, F. (1996). Un pionnier de la prospective, le ministère de Défense. In Lesourne, J., Stoffaës, CH. (Eds.), La prospective stratégique d'entreprise. Dunod, Paris.

Roubelat, F. (1998). Méthodologie prospective et recherche en management stratégique. Actes de la $7^{e}$ conférence de l'AIMS.

Roubelat, F. (2000). Scenario planning as a networking process. Technological Forecasting and Social Change, 65(1), 99-112. http://dx.doi.org/10.1016/S0040-1625(99)00125-0

Roubelat, F. (2001a). Réseaux prospectifs et stratégie d'entreprise. Revue Française de Gestion, 133.

Roubelat, F. (2001b). La prospective stratégique, des hommes et des organisations en réseaux. In Recueil d'hommages à Jacques Lesourne, Dunod, 286-305.

Roubelat, F. (2006). Scenarios to challenge strategic paradigms: lessons from 2025. Futures, 38(5), 519-527. http://dx.doi.org/10.1016/j.futures.2005.09.001

Scouarnec, A. (2008). Plaidoyer pour un renouveau de la prospective. Management \& Avenir, 5(19), 171-186. http://dx.doi.org/10.3917/mav.019.0171

Slaughter, R. A. (1997). Developing and Applying Strategic Foresight. ABN Report, 5(10), 13-27.

Smida, A. (2004). La prospective: entre ambition et pratique. Les DOCS D'ALEPH, 10.

Thiétart, R. A., \& Bergadaa, M. (1990). Experts s'abstenir. Harvard L'Expansion, 98-105.

Van der heijden, K. (1997). Scenarios, strategies and the strategy process. Nijenrode University Press.

Van der heijden, K. (2004). Can internally generated futures accelerate organizational learning scenario? Futures, 36, 145-159. http://dx.doi.org/10.1016/S0016-3287(03)00143-5

Vecchiato, R. (2012). Environmental uncertainty, foresight and strategic decision making: An integrated study. Technological Forecasting \& Social Change, 79, 436-447. http://dx.doi.org/10.1016/j.techfore.2011.07.010

Note

Note 1. http://www.tunisieindustrie.nat.tn

\section{Copyrights}

Copyright for this article is retained by the author(s), with first publication rights granted to the journal.

This is an open-access article distributed under the terms and conditions of the Creative Commons Attribution license (http://creativecommons.org/licenses/by/3.0/). 